\title{
The third nervous system in the lung: physiology and clinical perspectives
}

The autonomic nervous system controls many aspects of pulmonary function' and, until recently, it was thought that this was achieved entirely by means of classical cholinergic and adrenergic mechanisms. This view has recently been challenged by the demonstration of a third nervous system in the airways (fig). Although the identities of the neurotransmitters in this newly recognised nervous system are not certain, there is increasing evidence that they are peptides. This third nervous system is of particular interest as it is the predominant inhibitory nervous pathway to human airway smooth muscle and this raises the possibility that a functional defect in this nervous system might underlie bronchial hyperreactivity in asthma. The recognition that a third component of the autonomic nervous system regulates airway smooth muscle tone and other aspects of lung physiology has stimulated great interest, since it may provide new insights into diseases such as asthma and chronic obstructive lung disease, and may also lead to novel therapeutic approaches.

\section{A third component of the autonomic nervous system}

The existence of a nervous system in the gastrointestinal tract which is neither adrenergic nor cholinergic has been established for many years. Non-adrenergic, non-cholinergic (NANC) nerves control gut motility and secretions and have been demonstrated in vertebrates from fish to man. ${ }^{23}$ Indeed, the presence of NANC nerves in primitive vertebrates indicates that this nervous system developed early in evolution. The third nervous system has also been demonstrated in the urogenital tract, the eye, and the cardiovascular system. ${ }^{3}$ Because the airways develop embroyologically from the foregut it is not surprising to find that NANC nerves are also present in the lung.

\section{NANC nerves in the airways}

Inhibitory nerves which relax toad lungs and which

Address for reprint requests: Dr Peter J Barnes, Department of Medicine (Respiratory Division), Royal Postgraduate Medical School, Hammersmith Hospital, London W12 0HS. are neither adrenergic nor cholinergic were described by Campbell in 1971.4 Since then NANC nerves which relax airway smooth muscle have been found in several species, including man. ${ }^{5-8}$ In these studies airway strips are mounted in an organ bath and stimulated by an electrical current that selectively activates nerves. In guinea pig tracheal strips electrical field stimulation produces an initial contraction that is blocked by the anticholinergic drug atropine and therefore due to acetylcholine release from cholinergic nerves. The initial contraction is followed by a relaxation, which is only partially inhibited by $\beta$ adrenergic blockers. ${ }^{56}$ Thus, although a component of the inhibitory response is adrenergic, there is a component that is nonadrenergic. The nerve toxin tetrodotoxin abolishes these responses to field stimulation and proves that they are mediated by nerves (which must be postganglionic), and not due to a direct effect on smooth muscle. Thus guinea pig trachea appears to have excitatory cholinergic nerves and inhibitory nerves which are both adrenergic and non-adrenergic. In similar studies on human airway smooth muscle a cholinergic contractile component is also demonstrable, but the inhibitory response is unaffected by adrenergic blockade..$^{78}$ This indicates, rather surprisingly, that there is no functional sympathetic innervation of human airway smooth muscle and that inhibitory nerves are non-adrenergic. The absence of sympathetic nerves in human airway smooth muscle is supported by histological studies showing an absence of adrenergic nerve terminals within smooth muscle, ${ }^{79}$ by studies showing a lack of effect of cocaine (a neuronal uptake inhibitor) on noradrenaline dose-response curves, ${ }^{10}$ and by the lack of effect of tyramine (which directly releases noradrenaline from nerve terminals) on airway function in man. "There are, of course, adrenergic receptors in airway smooth muscle,,$^{12}$ and these are presumably regulated by circulating adrenaline. ${ }^{13}$ NANC nerves appear to be the only neural inhibitory pathway in human airway smooth muscle from the trachea to the smallest bronchi, ${ }^{7}$ and for this reason there is particular interest in their physiological role and regulation.

NANC nerves have also been demonstrated in 


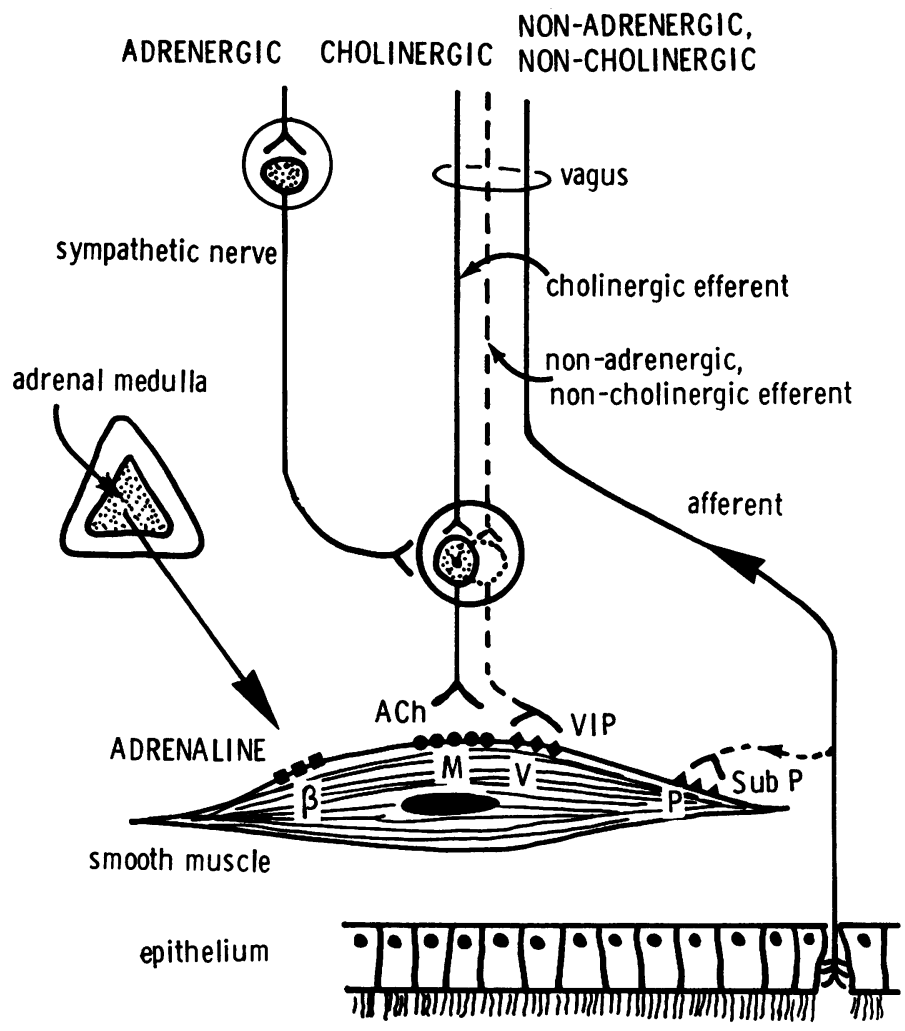

airway lumen

\begin{abstract}
Innervation of human airway smooth muscle: the three components of the autonomic nervous system. In addition to classical adrenergic and cholinergic pathways, there is a third component to the autonomic nervous system, shown by the dashed lines. The non-cholinergic, non-adrenergic pathway is inhibitory to airway smooth muscle, the neurotransmitter of which is likely to be vasoactive intestinal peptide (VIP). There may also be an excitatory non-cholinergic pathway, which may consist of collateral branches of afferent nerves which release substance P. Specific receptors for these neurotransmitters present on airway smooth muscle cells: $\beta-\beta$ adrenergic, $M-$ muscarinic cholinergic, $V-V I P$, and $P-$ substance $P$ receptors. ACh-acetylcholine.
\end{abstract}

cats and guinea pigs in vivo by electrical stimulation of the vagus nerve after cholinergic and adrenergic blockade. ${ }^{14-16}$ Stimulation of this pathway produces pronounced and long lasting bronchodilatation. This response can be inhibited by ganglion blockers, suggesting that these NANC nerves are preganglionic as well as postganglionic. ${ }^{14}$ It has not yet been possible to establish whether NANC nerves mediate bronchodilation in human airways in vivo, although such studies should be possible with pharmacological blockade and reflex stimulation.

NANC nerves also regulate secretion of airway mucus in animals. Stimulation of the vagus nerves promotes mucus secretion in cat trachea, which is reduced but not abolished by cholinergic and adrenergic blockers ${ }^{17}$; and electrical field stimulation of ferret tracheal segments in vitro also indicates that NANC nerves stimulate mucus secretion. ${ }^{18}$ NANC nerves may also mediate relaxation of pulmonary blood vessels. ${ }^{19}$

\section{The search for the neurotransmitter}

Although it has been possible to demonstrate the existence of NANC nerves in the lung both in vitro and in vivo, it is difficult to investigate the physio- 
logical role of this nervous system until the neurotransmitter has been identified and a specific blocker developed. Burnstock originally proposed that the neurotransmitter might be a purine nucleotide such as adenosine triphosphate (ATP) or adenosine, since in the gut these purines are released on nerve stimulation and both exogenous ATP and adenosine mimic some of the effects of NANC nerve stimulation. $^{2}$ These nerves were therefore termed purinergic. The evidence is, however, against a purine as the neurotransmitter of NANC nerves in the airways. Although ATP relaxes isolated guinea pig airway smooth muscle, ${ }^{2021}$ its antagonist quinidine does not block NANC relaxation either in vitro or in vivo, ${ }^{202223}$ nor does the purine uptake inhibitor dipyridamole enhance non-adrenergic bronchodilation. ${ }^{21} 22$

More recent studies suggest that the neurotransmitter may be a regulatory peptide, so that NANC nerves are probably "peptidergic." There is now rather convincing evidence that several regulatory peptides may be neurotransmitters or neuromodulators in the gut. ${ }^{24}$ Electron microscopy has revealed different types of neurosecretory granules in autonomic nerve terminals in the gut ${ }^{25}$ : small clear vesicles which contain acetylcholine and small dense granules containing catecholamines represent cholinergic and adrenergic nerves. In addition, there are large dense vesicles resembling neurosecretory granules in the central nervous system that are known to contain peptides, and which were therefore called " $p$ " type granules. ${ }^{25}$ Ultrastructural immunocytochemical techniques have now confirmed that peptides such as substance $P$ and vasoactive intestinal peptide (VIP-see below) are localised to these granules. ${ }^{24}$ Similar " $p$ " type granules have also been described in nerves of the airways, ${ }^{26}$ suggesting that peptides may function as neurotransmitters of NANC nerves in the lung. Several regulatory peptides have recently been identified by radioimmunoassay in lung tissue of several species (including man); they include VIP, substance $P$, bombesin, cholecystokinin, and somatostatin. ${ }^{27}{ }^{28}$ Immunocytochemical studies have demonstrated that some of these peptides are localised to nerves within the airway.

\section{VIP and NANC neurotransmitter}

There is now considerable evidence in favour of VIP as a neurotransmitter of NANC nerves in the airway. VIP is a 28 amino acid peptide which was originally discovered by Said as a vasoactive substance in lung extracts, ${ }^{29}$ and was later shown to relax airway smooth muscle in vitro. ${ }^{30}$ More recently VIP has been found in both animal and human lungs local- ised to neurones and nerve terminals in airway smooth muscle (particularly in the upper airways), around submucosal glands, beneath airway epithelial cells, and in bronchial and pulmonary vessels. ${ }^{27}{ }^{31}{ }^{32}$ In addition, VIP is localised in airway ganglia in both neurones and preganglionic nerve terminals (CB Basbaum, PJ Barnes, unpublished observations). VIP produces prolonged relaxation of airway smooth muscle in vitro, which is unaffected by adrenergic or cholinergic blockers. ${ }^{21} 2230$ Moreover, VIP mimics the electrophysiological changes in airway smooth muscle produced by NANC nerve stimulation. ${ }^{21} 22$ In vivo inhaled VIP protects against histamine induced bronchoconstriction in $\operatorname{dogs}^{19}$ and guinea pigs, ${ }^{33}$ and infused VIP reverses serotonin induced bronchoconstriction in cats. ${ }^{34}$ In isolated human airways VIP has a small relaxant effect $^{8}$ and inhaled VIP has only a weak protective effect against histamine induced bronchoconstriction compared with a $\beta$ agonist. ${ }^{35}$ VIP given by infusion has a small bronchodilator effect and protects against histamine induced wheeze in asthmatics, ${ }^{36}$ although the cardiovascular actions of the infused peptide may have accounted for these effects. The relative lack of effect of VIP in human airways by no means excludes it as a possible neurotransmitter as the exogenous peptide may have relatively poor access to airway smooth muscle compared with peptide released from nerves within the muscle.

Electrical field stimulation of tracheobronchial preparations releases VIP into the bathing medium and the release is blocked by tetrodotoxin, indicating that VIP is derived from nerve stimulation. ${ }^{22}{ }^{37}$ Furthermore, the amount of VIP released is related to the magnitude of NANC relaxation. ${ }^{37}$ Unfortunately no specific blocker of VIP is yet available, but prolonged incubation of airway smooth muscle with VIP reduces subsequent responses to VIP (tachyphylaxis) and also reduces the magnitude of NANC nerve relaxation in cats. ${ }^{21}$ Preincubation of guinea pig trachea with a specific antibody to VIP also reduces the NANC relaxation response. ${ }^{37}$ Taken together, all this evidence points strongly to VIP as a likely candidate for the role of neurotransmitter of non-adrenergic inhibitory nerves. Conclusive proof, particularly in human airways, awaits development of a specific blocker.

\section{Other VIPergic nerves in lung}

VIPergic nerves may regulate other aspects of pulmonary function, since they are widely distributed within the lung. VIPergic nerves are closely associated with airway submuscosal glands ${ }^{27} 32$ and in vitro VIP stimulates secretion of mucus from tracheal 
glands in ferrets. ${ }^{38}$ VIP is therefore a possible neurotransmitter of non-adrenergic, noncholinergic nervous secretion of mucus. VIP has an unexpected inhibitory effect on secretion of macromolecules from isolated human airways, however. ${ }^{39}$ VIPergic nerves are also present in close association with the airway epithelium and VIP is a potent stimulant of active ion transport and therefore water secretion across airway epithelium in dogs. ${ }^{40}$ Thus VIPergic nerves may regulate secretion of both mucus and water, and so influence mucociliary transport in the airways.

VIP is a potent vasodilator in the pulmonary circulation, and the finding of a rich supply of VIPergic nerves in pulmonary vessels indicates that it is quite likely to be the mediator for NANC nervous vasodilation in the lung. ${ }^{19}$ VIPergic nerves may also modulate cholinergic neurotransmission in airway ganglia. VIP inhibits antigen induced release of histamine from sensitised guinea pig lung fragments in vitro $^{4}$ and this raises the possibility that VIPergic nerves also regulate mast cell mediator secretion.

\section{Mode of action of VIP}

VIP is released from nerve terminals and stimulates specific receptors, which have been demonstrated in lung membranes by radioligand binding techniques with labelled VIP.42 Preliminary results with autoradiography of radiolabelled VIP indicate that the receptors are widely distributed within the lung (A Nimmo et al, unpublished observations). Stimulation of VIP receptors activates adenylate cyclase, thereby increasing the cellular concentration of cyclic AMP. Thus VIP increases the cyclic AMP content of lung and trachea, ${ }^{43}$ and this increase in cyclic AMP has been localised immunocytochemically to epithelial cells, submucosal glands, and airway smooth muscle cells. ${ }^{44}$ Beta adrenoceptor agonists also activate adenylate cyclase and the physiological effects of VIP on the airways are similar to those of $\beta$ agonists. It is possible that there may be a deficiency in VIP receptors in the airways of asthmatic patients, in the same way that $\beta$ adrenoceptor dysfunction has been postulated as an underlying mechanism of asthma. ${ }^{45}$ The protective effect of VIP against histamine induced bronchoconstriction is not, however, correlated with the degree of bronchial hyperreactivity, which argues against a defect in VIP receptors that contributes to this phenomenon..$^{35}$

VIPergic nerves are usually distributed with cholinergic nerves. Ultrastructural evidence suggests that VIP may coexist in the same nerve terminals as acetylcholine and may therefore function as a cotransmitter ${ }^{46}$ Possibly VIP, in addition to a direct effect on VIP receptors of target cells, also has a prejunctional effect on acetylcholine release or, as demonstrated in submaxillary glands, ${ }^{47}$ an effect on postjunctional cholinergic receptors. The relationship between cholinergic and VIPergic neurotransmission in the lung is worthy of further exploration.

\section{Substance $\mathbf{P}$ and non-cholinergic excitatory nerves}

Substance $P$, an 11 amino acid peptide, is localised to afferent nerves in the airways of several species, including man. ${ }^{2748}$ Substance $P$ immunoreactive nerves in the airway are found beneath and within the airway epithelium, around blood vessels, and to a lesser extent within airway smooth muscle. Treatment of animals with capsaicin, a pungent extract of red peppers, releases substance $P$ from sensory nerves and depletes the lung of substance $P .{ }^{49}$ Substance $P$ contracts airway smooth muscle of several species, including man. ${ }^{4850}$ Moreover, capsaicin is capable of inducing a similar contraction, indicating release of substance $\mathbf{P}$ from intrinsic nerves within airway smooth muscle. ${ }^{50}$ In rats substance $P$ and capsaicin induce oedema of the airway mucosa by increasing vascular permeability, and depletion of substance $P$ nerves by neonatal capsaicin pretreatment prevents irritants such as cigarette smoke from causing mucosal oedema, suggesting that substance $P$ nerves mediate this effect. ${ }^{51}$ Substance $P$ also stimulates airway mucus secretion. ${ }^{51}$ Electrical stimulation of guinea pig bronchi in vitro produces a component of bronchoconstriction which is not inhibited by atropine, ${ }^{5253}$ but which is blocked by a substance $\mathrm{P}$ antagonist. ${ }^{52}$ In human airways, however, this non-cholinergic non-adrenergic excitatory nervous pathway was found in only one out of eight airways tested. ${ }^{50}$ In man inhalation of capsaicin induces cough and transient bronchoconstriction which is seen in both normal and asthmatic subjects, ${ }^{54}$ and substance $P$ is a bronchoconstrictor when given by inhalation ( $R$ Fuller et al, unpublished observations).

\section{Other regulatory peptides in lung}

Several other peptides have recently been found in lung. Peptide histidine isoleucine (PHI) is structurally similar to VIP and is localised to VIPergic nerves. ${ }^{55} \mathrm{PHI}$, like VIP, relaxes airway smooth muscle but stimulates specific PHI receptors. It is therefore another candidate for the role of neurotransmitter of NANC nerves and probably functions in conjunction with VIP. A newly discovered peptide, neuropeptide Y (NPY), has also been localised to nerves in the lung and is associated with sympathetic nerves, so that it is found in blood vessels rather 
than airway smooth muscle in human airways. ${ }^{2856}$ Cholecystokinin and somatostatin, which function as neurotransmitters in the gut, have also been identified in airways, although in concentrations too low to permit localisation at present. ${ }^{27}$ Another peptide, bombesin, causes bronchoconstriction in high concentrations, ${ }^{57}$ but is localised to neuroendocrine cells rather than nerves. ${ }^{27}$ As assay techniques and isolation procedures improve it is almost certain that other peptides will be identified in the respiratory tract.

\section{Clinical significance of NANC nerves in lung}

The recent discovery of NANC innervation in the lung has important clinical implications and may lead to further understanding and new treatment of several pulmonary diseases. Asthmatic subjects show exaggerated bronchoconstrictor responses to a wide variety of stimuli, and, because changes in airway tone are rapid, it is suggested that abnormal nervous control of the airway is the underlying mechanism of bronchial hyperreactivity, with a preponderance of excitatory (cholinergic and $\alpha$ adrenergic) or a deficiency of inhibitory $(\beta$ adrenergic) control. Although minor abnormalities in classical autonomic mechanisms have been found in asthma, they are insufficient to account for bronchial hyperreactivity.' The recent discovery of nonadrenergic inhibitory nerves in the airways has therefore raised the possibility that this nervous system is defective in asthma, particularly since it is the only neural inhibitory system in human airways. Non-adrenergic inhibitory nerves may exert a braking effect on bronchoconstriction, and a functional defect would presumably lead to exaggerated responses to constrictor stimuli. Unfortunately the absence of specific blocking drugs for these nerves makes it difficult to evaluate this possibility at present, although it seems likely that specific inhibitors of putative neurotransmitters such as VIP will be developed soon. There are analogies between asthma and other conditions in which there is abnormal smooth muscle control and in which abnormalities of peptidergic nerves have been found. In Hirschprung's disease there is contraction of colonic smooth muscle and an absence of ganglia and peptidergic nerves in the colon wall. ${ }^{58} \mathrm{~A}$ similar reduction in VIPergic nerves has also been found in the wall of unstable bladders. ${ }^{58}$

The demonstration of substance $P$ containing nerves in human airways is also clinically relevant since this peptide can produce bronchoconstriction, bronchial mucosal oedema, and mucus hypersecretion, all of which are features of asthma. In human skin substance $P$ produces a weal and flare response when injected intradermally ${ }^{48}$ and causes the direct release of histamine from human skin mast cells in vivo (D Heavey et al, unpublished observations). If this were to occur in the airway then stimulation of substance $P$ nerves could lead to a local axon reflex, with release of substance $P$, resulting in bronchial smooth muscle contraction and mucosal oedema. It is tempting to speculate that in asthma these substance $P$ nerves may be sensitised by inflammation, or that airway mast cells may be more sensitive to substance $P$, so that constrictor responses become exaggerated.

The clinical implications of NANC innervation in the lungs are only now being appreciated, but abnormal function of non-adrenergic inhibitory nerves (which are probably VIPergic and PHIergic) or of non-cholinergic excitatory nerves (probably substance $P$ containing) could underly bronchial hyperreactivity in asthma. NANC nerves also influence airway mucus secretion and pulmonary vascular tone, so that there are important implications for chronic bronchitis and for pulmonary vascular disease. Future development of novel drugs which interact with NANC neurotransmission should lead to new forms of treatment for these diseases. It is certain that much more will be heard of NANC nerves and their neurotransmitters in the lungs as their physiology and pathophysiology are unravelled.

\section{PETER J BARNES \\ Department of Medicine (Respiratory Division) \\ Royal Postgraduate Medical School Hammersmith Hospital \\ London}

\section{References}

' Nadel JA, Barnes PJ. Autonomic regulation of the airways. Ann Rev Med 1984;35:451-67.

${ }^{2}$ Burnstock G. Purinergic nerves. Pharm Rev 1972; 24:509-81.

${ }^{3}$ Burnstock G. Comparative studies of purinergic nerves. J Exp Zool 1975; 194:103-34.

${ }^{4}$ Campbell G. Autonomic innervation of the lung musculature of a toad (Bufo marinus). Comp Gen Pharmacol 1971;2:281-6.

${ }^{5}$ Coburn RF, Tomita T. Evidence for nonadrenergic inhibitory nerves in guinea pig trachealis muscle. Am J Physiol 1973;224:1072-80.

${ }^{6}$ Richardson JB. Nonadrenergic inhibitory innervation of the lung. Lung 1981;159:315-22.

${ }^{7}$ Richardson J, Beland J. Nonadrenergic inhibitory nervous system in human airways. J Appl Physiol 1976;41:764-71.

${ }^{8}$ Davis C, Kannan MS, Jones TR, Daniel EE. Control of human airway smooth muscle: in vitro studies. J Appl Physiol 1982;53:1080-7.

' Sheppard MN, Kurian SS, Henzen-Logmans SC et al. 
Neurone-specific enolase and S-100: new markers for delineating the innervation of the respiratory tract in man and other mammals. Thorax 1983;38:333-40.

${ }^{10}$ Zaagsma J, Van der Heijden PJCM, Van der Schaar MWG, Bank CMC. Comparison of functional betaadrenoceptor heterogeneity in central and peripheral airway smooth muscle of guinea pig and man.J Recept Res 1983;3:89-106.

"Ind PW, Scriven AJI, Dollery CT. Use of tyramine to probe pulmonary noradrenaline release in asthma. Clin Sci 1983;64:9P.

12 Barnes PJ. Adrenergic receptors of normal and asthmatic airways. In: Zaagsma J, ed. Receptors and chronic obstructive lung disease. Amsterdam: Exerpta Medica, 1984;72-9.

${ }^{13}$ Barnes PJ. Endogenous plasma adrenaline in asthma. Eur J Respir Dis 1983;64:559-63.

${ }^{14}$ Diamond L, O'Donnell M. A non-adrenergic vagal inhibitory pathway to feline airways. Science 1980; 208: $185-8$.

is Irvin CG, Boileau R, Tremblay J, Martin RR, Macklem PT. Bronchodilatation: noncholinergic, nonadrenergic mediation demonstrated in vivo in the cat. Science 1980;207:791-2.

${ }^{16}$ Chesrown SE, Venugopalan CS, Gold WM, Drazen JM. In vivo demonstration of nonadrenergic inhibitory innervation of the guinea pig trachea. J Clin Invest 1980;65:314-20.

${ }^{17}$ Peatfield AC, Richardson PS. Evidence for noncholinergic, non-adrenergic nervous control of mucus secretion into the cat trachea. J Physiol 1983; 342:335-45.

${ }^{18}$ Borson DB, Charlin M, Gold BD, Nadel JA. Nonadrenergic noncholinergic nerves mediate secretion of macromolecules by tracheal glands of ferrets. Fed Proc 1982;42:1715.

${ }^{14}$ Said SI. Vasoactive peptides in the lung, with special reference to vasoactive intestinal peptide. Exp Lung Res 1982;3:343-8.

${ }^{20}$ Kamikawa Y, Shimo Y. Pharmacological differences in non-adrenergic inhibitory response and of ATPinduced relaxations in guinea pig tracheal strip chains. $J$ Pharm Pharmacol 1976;28:854-5.

${ }^{21}$ Ito Y, Takeda K. Non-adrenergic inhibitory nerves and putative transmitters in the smooth muscle of cat trachea. J Physiol 1982;330:497-511.

${ }^{22}$ Cameron AC, Johnson CF, Kirkpatrick CT, Kirkpatrick MCA. The quest for the inhibitory neurotransmitter in bovine tracheal smooth muscle. $Q J$ Exp Physiol 1983;68:413-26.

${ }^{23}$ Irvin CG, Martin RR, Macklem PT. Non purinergic nature and efficacy of non-adrenergic bronchodilation. J Appl Physiol 1982;52:562-9.

${ }^{24}$ Costa M, Furness JB. Neuronal peptides in the intestine. Br Med Bull 1982;38:247-52.

${ }^{25}$ Baumgarten HG, Holstein AF, Owman CTI. Auerbach's plexus of mammals and man-electron microscopical identification of three different types of neuronal processes in myenteric ganglia of the large intestine from rhesus monkeys, guinea pigs and man. Z Zellforsch 1970;106:376-97.

${ }^{26}$ Daniel EE, Davis C, Jones T, Kannan MS. Control of airway smooth muscle. In: Airway reactivity. Mechanisms and clinical relevance. Hargreave FE, ed. Ontario: Astra, 1980:80-107.

${ }^{27}$ Polak JM, Bloom SR. Regulatory peptides in the respiratory tract of man and other animals. Exp Lung Res 1982;3:313-28.

${ }^{28}$ Hakanson R, Sundler F, Moghimzadeh E, Leander S Peptide-containing nerve fibres in the airways: distribution and functional implications. Eur J Respir Dis 1983;64, suppl 131:115-46.

${ }^{29}$ Said SI, Mutt V. Long acting vasodilator peptide from lung tissue. Nature 1969;224:699-700.

${ }^{30}$ Said SI, Kitamura S, Yoshida T, Preskitt J, Holden LD. Humoral control of airways. Ann NY Acad Sci 1974;221: $103-14$.

${ }^{31}$ Uddman R, Sundler F. Vasoactive intestinal peptide nerves in human upper respiratory tract. Otorhinolaryngology 1979;41:221-6.

${ }^{32}$ Dey RD, Shannon WA, Said SI. Localization of VIPimmunoreactive nerves in airways and pulmonary vessels of dogs, cats and human subjects. Cell Tissue Res 1981;220:231-8.

${ }^{33}$ Cox CP, Lerner MR, Wells JH, Said SI. Inhaled vasoactive intestinal peptide (VIP) prevents bronchoconstriction induced by inhaled histamine. Am Rev Respir Dis 1983;127:249.

${ }^{34}$ Diamond L, Szarek JL, Gillespie MN, Altiere RJ. In vivo bronchodilator activity of vasoactive intestinal peptide in the cat. Am Rev Respir Dis 1983; 128:827-32.

${ }^{35}$ Barnes PJ, Dixon CMS. The effect of inhaled vasoactive intestinal peptide on bronchial reactivity to histamine in man. Am Rev Respir Dis (in press).

${ }^{36}$ Morice A, Unwin RJ, Sever PS. Vasoactive intestinal peptide causes bronchodilatation and protects against histamine-induced bronchoconstriction in asthmatic subjects. Lancet 1983;ii:1225-6.

${ }^{37}$ Matsuzaki Y, Hamasaki Y, Said SI. Vasoactive intestinal peptide: a possible transmitter of nonadrenergic relaxation of guinea pig airways. Science 1980; 210:1252-3.

${ }^{38}$ Peatfield AC, Barnes PJ, Bratcher C, Nadel JA, Davis B. Vasoactive intestinal peptide stimulates tracheal submucosal gland secretion in ferret. Am Rev Respir Dis 1983;128:89-93.

${ }^{39}$ Coles SJ, Said SI, Reid LM. Inhibition by vasoactive intestinal peptide of glycoconjugate and lysozyme secretion by human airways in vitro. Am Rev Respir Dis 1981;124:531-6.

${ }^{40}$ Nathanson I, Widdicombe JH, Barnes PJ. Effect of vasoactive intestinal peptide across dog tracheal epithelium. J Appl Physiol 1983;55:1844-8.

${ }^{41}$ Undem BJ, Dick EC, Buckner CK. Inhibition by vasoactive intestinal peptide of antigen-induced histamine release from guinea pig minced lung. Eur $J$ Pharmacol 1983;88:247-50.

42 Robberecht P, Chatelain P, De Neef P, et al. Presence of vasoactive intestinal peptide receptors coupled to adenylate cyclase in rat lung membranes. Biochim Biophys Acta 1981;678:76-82.

${ }^{43}$ Frandsen EK, Krishna GA, Said SI. Vasoactive intestinal polypeptide promotes cyclic adenosine $3^{\prime}, 5^{\prime}$-monophosphate accumulation in guinea pig trachea. $B r J$ Pharmacol 1978;62:367-9.

${ }^{44}$ Lazarus SC, Basbaum CB, Barnes PJ, Gold WM. Mapping of vasoactive intestinal peptide receptors using cyclic AMP immunocytochemistry. Am Rev Respir Dis 1983;127:274.

${ }^{45}$ Szentivanyi A. The beta adrenergic theory of the atopic abnormality in bronchial asthma. J Allergy 1968; 
42:203-32.

${ }^{46}$ Schultzberg M, Hokfelt T, Lundberg JM. Coexistence of classical transmitters and peptides in the central and peripheral nervous system. Br Med Bull 1982; 38:309-13.

${ }^{47}$ Lundberg JM, Hedlund B, Bartfai T. Vasoactive intestinal polypeptide enhances muscarinic ligand binding in cat submandibular salivary gland. Nature 1982; 295: 147-9.

${ }^{48}$ Pernow B. Substance P. Pharm Rev 1983;35:85-141.

${ }^{49}$ Lundberg JM, Brodin E, Saria A. Effects and distribution of vagal capsaicin-sensitive substance $P$ neurons with special reference the trachea and lungs. Acta Physiol Scand 1983;119:243-52.

${ }^{\text {so }}$ Lundberg JM, Martling C-R, Saria A. Substance P and capsaicin-induced contraction of human bronchi. Acta Physiol Scand 1983;119:49-53.

${ }^{51}$ Lundberg JM, Saria A. Capsaicin-induced desensitisation of the airway mucosa to cigarette smoke, mechanical and chemical irritants. Nature 1983;302:251-3.

52 Lundberg JM, Saria A, Brodin E, Rossell S, Folkers K. A substance $P$ anagonist inhibits vagally induced increase in vascular permeability and bronchial smooth muscle contraction in the guinea pig. Proc Natl Acad Sci USA 1983;80:1120-4.

${ }^{53}$ Andersson RGG, Grundstrom N. The excitatory noncholinergic, non-adrenergic nervous system of the guinea-pig airways. Eur J Respir Dis 1983;64, suppl 131:141-57.

s4 Fuller RW, Dixon CMS, Barnes PJ. The acute fall in airway conductance in man following $\mathrm{C}$-fiber stimulation by capsaicin. Am Rev Respir Dis 1984;129:A235 (abstract).

55 Christofides ND, Yiangou Y, Piper PJ, et al. Distribution of PHI in the mammalian tract and some aspects of its pharmacology. Regul Peptides 1982;4:359.

${ }^{56}$ Sheppard MN, Polak JM, Allen JM, Bloom SR. Neuropeptide tyrosine: a newly discovered peptide is present in the mammalian respiratory tract. Thorax 1984;39:326-30.

${ }^{57}$ Impicciatore M, Bertaccini G. The bronchoconstrictor action of the tetradecapeptide bombesin in the guinea pig. J Pharm Pharmacol 1973;25:812-5.

58 Polak JM, Bloom SR. Regulatory peptides: key factors in the control of bodily functions. $\mathrm{Br}$ Med $J$ 1983;286: 1461-6. 